\title{
Testing and Controlling for Common Method Variance: A Review of
}

\section{Available Methods}

\author{
Shehnaz Tehseen * $\quad$ T. Ramayah ${ }^{\dagger} \quad$ Sulaiman Sajilan ${ }^{\ddagger}$
}

\begin{abstract}
Several studies have debated over the prevalence of Common Method Variance (CMV) in organizational research. This paper highlights various procedural and statistical remedies to assess and control common method variance in any organizational study. It has been recognized that Common Method Variance $(C M V)$ may significantly influence the research findings if it is not controlled properly through procedural and statistical remedies. However, researchers usually do not use all procedural remedies to remove potential impacts of CMV. Therefore, statistical remedies are strongly suggested to control and remove effects of CMV from data analysis. We have mentioned some common and effective statistical remedies from existing literature that have been widely used and recommended to control the effects of CMV. Moreover, we also discuss the challenge of $C M V$ in relation to entrepreneurship studies and illustrate the problem utilizing an analysis of entrepreneurial competencies and business growth. In addition, we describe the possible solutions for minimizing the impact of common method bias by using the combination of several methods. This study strongly recommends using both procedural and statistical remedies to test and control the impacts of CMV from the research study.
\end{abstract}

Keywords: Common method variance, procedural remedies, statistical remedies, Harman's single-factor test, partial correlation procedures, correlation matrix procedure, MLMV approach.

\section{Introduction}

The researchers of social science have to deal and analyze the self-reported data such as data on respondents' personality, behaviors, and perceptions on various issues, i.e. personality traits, entrepreneurial and managerial behaviors, business success, and business environment etc. The questionnaire survey is commonly used for data collection in entrepreneurship and management research. These surveys provide the information that is used to measure the independent as well as dependent variables in a data analysis. However, the estimated impact of one variable on other variable is at risk of being biased due to CMV which is the systematic variance shared among the variables Jakobsen and Jensen (2015), and is usually introduced to the measures by the method of measurement rather than the theoretical constructs represented by the measures (Jakobsen \& Jensen, 2015; Podsakoff, MacKenzie, \& Podsakoff, 2012; Podsakoff, MacKenzie, Lee, \& Podsakoff,

\footnotetext{
* PhD Scholar and Excellent Graduate Assistant, Universiti Kuala Lumpur Business School, 50300, Malaysia.

E-mail: shehnaz_teh@yahoo.com

† Professor, School of Management, Universiti Sains Malaysia, 54100 Kuala Lumpur, Malaysia.

E-mail: ramayah@usm.my

$\ddagger$ Professor, Universiti Kuala Lumpur Business School, 50300, Malaysia.
} 
2003). For instance, if the impacts of entrepreneurs' competencies on SMEs' growth are estimated using only entrepreneurs' perceptions on their own competencies and on their business growth performance, the estimated impact may be biased if some respondents overstate both competencies and growth performance due to the tendency to assess themselves in too positive manner or because of social desirability. In this case, a positive correlation is produced between the two variables when the same respondent is used as a source for obtaining the measures of both the independent and dependent variables. Therefore, the estimated impacts may suffer from common method bias. Thus, survey methods introduce a serious methodological challenge that is the risk of common method bias Jakobsen and Jensen (2015) which has not gained much attention as a unique topic in entrepreneurship research. The purpose of this paper is, therefore, to fill the knowledge gap by describing CMV as a central topic in the entrepreneurship research. Although a number of organizational studies have debated on the serious challenges of CMV that may arise due to various factors such as common method and items' characteristics (Doty \& Glick, 1998). However, such studies did not mention the details of various steps that are needed to follow in order to conduct various statistical tests to control the CMV from a certain study. We have provided all necessary steps for selected statistical approaches that are essential to assess and remove the influence of CMV from data analysis. We have mentioned the most suitable statistical remedies for PLS models. We believe that researchers can easily follow the given steps to conduct each of the CMV control tests. Moreover, in next sections, we have described the definition of $\mathrm{CMV}$, potential sources of $\mathrm{CMV}$, and procedural as well as statistical approaches to control it. Furthermore, we have described a practical example that how common method bias may appear in a specific study and provided illustrations of various selected statistical tests based on our real field work data to test and remove the impacts of common bias from the study. Since, the Smart PLS software was used to analyze the data, therefore, we have emphasized in describing only those statistical remedies that were considered more suitable for PLS models.

\section{What is Common Method Variance (CMV)?}

In recent decades, the empirical research within organizational studies has devoted much attention to the issue of CMV and how it may bias the findings of empirical analyses that use the same respondents as a source for obtaining data (Jakobsen \& Jensen, 2015). According to Doty and Glick (1998), CMV occurs when the systematic variance is introduced into the measures by the measurement technique. Similarly, Richardson, Simmering, and Sturman (2009) defined CMV as the systematic error variance that is shared among variables which are measured with the same source or method. This systematic error variance can cause common method bias and can also bias the estimated relationships among variables or measures (Jakobsen \& Jensen, 2015; Campbell \& Fiske, 1959). The common method can be considered as a third variable that impacts the estimated relationship among variables in a systematic way, i.e. either inflates or deflates the estimated relationship among variables of interest (Jakobsen \& Jensen, 2015). The general method bias or same source bias may arise while utilizing self-report measures from the same sample during a survey (Podsakoff \& Todor, 1985). This general method bias or 
same source is known as Common Method Variance (CMV). It represents the amount of spurious correlation among the variables that may be generated by utilizing the same method (i.e. survey) in order to measure each variable. Moreover, Reio (2010) stated that CMV threats the validity of conclusions about the constructs' association and creates the systematic bias in a study either by inflating or deflating the correlations. CMV has been referred to the variance of measurement method rather than to the constructs' variance that is represented by the measures (Podsakoff et al., 2003; Campbell \& Fiske, 1959). CMV leads to a false internal consistency which is an apparent correlation between the variables created by their common source. For instance, this may occur if same respondents are asked to evaluate their own competencies and their firm's growth performance in the same survey. Such cases can create false correlations through self-report data if the respondents provide consistent answers to all survey questions that are even not related. Therefore, CMV is often a problem and researchers are required to control it through all possible ways (Podsakoff et al., 2003). CMV has potential to threat the validity of data when the participants respond to all survey items in a single sitting (Burton-Jones, 2009).

\section{Common Sources of CMV}

The main CMV's sources include the use of only one type of item context, respondent, measurement context, and item characteristics (Reio, 2010; Podsakoff et al., 2003). Therefore, it is essential to examine CMV while collecting the data through self-reported surveys or questionnaires, particularly, when the same respondent is the only source of getting data on predictor as well as on criterion variables (Podsakoff et al., 2003). Similarly, Podsakoff and Todor (1985) had earlier noted that same source bias may arise while obtaining the self-reported measures from the same sample. Furthermore, Podsakoff et al. (2003) have explored four common sources of CMV; (a) the use of the same respondent to obtain the information for both dependent and independent variables; (b) the manner of items' presentation to respondents; (c) the context in which items are placed on a questionnaire; (d) and the contextual impacts (media, time, and location) used for measurement of the constructs (Chang, Van Witteloostuijn, \& Eden, 2010). However, bias produced by items' characteristics and by a common source has given much attention in the literature on CMV (Jakobsen \& Jensen, 2015). Some sources of CMV can be more worrisome than others, for instance, perceptual data from the single source (respondent) may be more problematic than the manner of items' presentation in the survey instrument. Similarly, the most worrisome CMV may occur when the same respondent is used getting data for both the independent and dependent variables under same measurement context, same item context and characteristics (Chang et al., 2010; Podsakoff et al., 2003). Particularly, CMV may result from certain tendencies that raters apply or that have the influence on their responses, while answering a survey on different measures (Liang, Saraf, $\mathrm{Hu}$, \& Xue, 2007). Therefore, such response bias has given more attention. Paulhus (1991) has described it as a systematic tendency to give the response to a range of items of the questionnaire on some basis other than the particular content. Social desirability is a well-known tendency of the respondent that refers to the tendency of respondents to give answers that make them look good (Paulhus, 1991; Ganster, Hennessey, \& Luthans, 
1983). For instance, if we survey business owners about their competencies, we must consider whether they may overstate their entrepreneurial competencies because of social desirability. This may lead to a problem if same owners will be asked to evaluate their organizational performance. Therefore, business owners who attach great importance to social desirability may overstate both their entrepreneurial competencies and organizational performance, on the other hand, the business owners with low social desirability will not tend to make these exaggerations. In such cases, the social desirability is a confounder that impacts the answers to both entrepreneurial competencies and organizational performance, which inflates the observed correlation among the constructs. CMV may be produced by the consistency motif that is the respondents' tendency to provide consistent answers across all survey items (Jakobsen \& Jensen, 2015; Podsakoff et al., 2003). Another response tendency constitutes the respondents' pervasive view of themselves and the world in general, that is captured by the concepts of positive or negative affectivity (Watson \& Clark, 1984). Negative affectivity is related to the respondent's negative emotions; on the other hand, the positive affectivity indicates the positive emotionality of the respondents (Jakobsen \& Jensen, 2015). Additionally, Watson and Clark (1984) noted that positive and negative affectivity consists of two separate dimensions. Moreover, CMV may arise from same raters' tendency to use or avoid to use the extreme choices on an item scale Bachman and O'Malley (1984) and the respondents' tendency to agree or disagree with behavioral/attitudinal statements regardless of specific content (Jakobsen \& Jensen, 2015; Baumgartner \& Steenkamp, 2001). The rater's transient mood state may also impact his/her answers to questions about the independent as well as dependent variables (Podsakoff et al., 2003). Jakobsen and Jensen (2015) stated that the main characteristic of the response tendencies is that they are highly stable across time.

The characteristics of a survey item may also produce the common method bias. According to Podsakoff et al. (2012), the complex, abstract or ambiguous items lead difficulty for respondents to properly respond and are more likely to cause method bias. As Podsakoff et al. (2003) already mentioned that respondents often develop their own understanding and idiosyncratic meanings of the ambiguous items that may increase random responding or respondents' systematic response tendencies. Furthermore, the item complexity may cause abstractness in the construct (Doty \& Glick, 1998). In such cases, the complex items make the task of responding difficult to answer on the basis of such complex items' content and increase the probability that respondents' systematic tendencies of response will impact their answer (Podsakoff et al., 2012). Similarly, method bias can be developed due to similar scale properties across different items Podsakoff et al. (2003); if the wording of items generate socially desirable responses Perry (1996); Nederhof (1985); or if items are worded only positively or negatively (Podsakoff et al., 2012). In addition, a number of other characteristics of items may lead method bias that may not solely result from the formulation of items (Jakobsen \& Jensen, 2015).

\section{Approaches to Control the Method Biases}

Many researchers such as (Podsakoff et al., 2012; Williams, Hartman, \& Cavazotte, 2010; Podsakoff et al., 2003) have mentioned two main approaches that can be used to control 
the method biases. For example, the first method to minimize the influence of method biases is by the careful designing procedure of the study and the second approach is to use statistical remedies in order to control the impact of common method bias after data collection. The procedural remedies are suggested to use prior data collection; on the other hand, statistical remedies are proposed to apply them after data collection before/after analyzing the data. Method biases can significantly impact on the reliabilities, validities of items, and on the covariation among latent constructs as well (Podsakoff et al., 2012). Chang et al. (2010) have strongly recommended using multiple remedies in order to assuage various concerns regarding CMV.

\section{The Procedural Remedies to Control the Common Method Bias}

In order to control method variance through procedural remedies, the common measures of the predictor (independent) variables and criterion (dependent) variables are needed to be identified and are then eliminated through study design. The items of predictor and criterion variables may be connected due to the specific format or wording, measurement structure of the questionnaire, or the respondent (Podsakoff et al., 2003). Therefore, several procedural remedies have suggested by Podsakoff et al. (2003) are summarized as below;

- The researcher should strive to get the measures of independent and dependent variables from different sources. Because obtaining or collecting data from the same source or rater is one of the main cause of the common method bias. Therefore, multiple sources of responses control the common method bias in the study. The benefit of this method is that it makes impossible for the mindset of the respondent to bias the observed relationships among the independent and dependent variables, this would eliminate the impacts of implicit theories, consistency motifs, social desirability tendencies, and various mood states. However, sometimes it is not possible to use under all situations, therefore, might result in the information loss when data on both the independent and dependent variables are not obtained from multiple users. Another drawback of this procedure is that this remedy may require more effort, time, and high cost.

- The other procedural remedy is the temporal, psychological or methodological separation of measured items/measurement of independent and dependent variables when the researcher is unable to collect data from multiple sources. Several ways are recommended to separate the measurements. For instance, one way is to create a temporal separation by introducing a time lag among the measurements of the independent and dependent variables. Another method is to create a psychological separation among measurements by using a cover letter to make it clear that the measurements of the independent variables are not related to the measurement of the dependent variables. Another technique is to methodologically separate the measures of variables by mentioning different circumstances to the respondents in order to complete the measurements of the independent and dependent variables. The measurements of the independent and dependent variables can be obtained by 
using different formats of response (such as Likert scale and open-ended questions); media (such as computer-based and face to face interviews), and locations (such as different sites or rooms). However, more effort, time, and expense are required to implement the method.

- The other procedural remedy is protecting the anonymity of the respondents and minimizing the evaluation apprehension. These procedures can minimize method bias at reporting or response editing stage. However, this method cannot be easily used along with above procedural remedies.

- Counterbalancing the order of measurement of the independent and dependent variable is another procedural remedy that can be used to neutralize some of the method biases related to items' embeddedness or question context. However, the main disadvantage of this approach is that it can disrupt the logical flow and makes not possible to use the funneling procedure which means the logical flow of general question to specific questions.

- The other possible procedural remedies include the improving of scale items through their careful construction. For instance, Tourangeau, Rips, and Rasinski (2000) mentioned that item ambiguity is the most common problem in the comprehension stage of response. Thus, the researchers should define unfamiliar terms, avoid vague concepts or provide their examples, keep questions specific, simple, and concise, do not use double-barreled and complicated syntax.

\section{Statistical Remedies}

The researchers can minimize the impacts of common method variance by using procedural remedies because when the effects of CMV are not eliminated or reduced then they may appear on the research findings. Sometimes it is not possible to totally remove the impact of CMV through procedural remedies because all procedural remedies are usually not applicable in all situations. For instance, researchers may not prefer multiple sources to collect data that need high cost, great effort, and more time. Thus, the other procedural remedies might reduce the impact of CMV to some extent. Therefore, it is useful to use statistical remedies to control CMV's impacts on research findings.

The accurate measurement of respondents' perceptions, opinions, behaviors, and attitudes is vital for managerial implications and theoretical conclusions (Yüksel, 2017). Yüksel (2017) concluded that the response bias leads toward serious doubts on the generalizability of conclusions. Thus, the severe impact of CMV on study's findings due to responses of same type of respondents makes the "generalizability" claims in the majority of entrepreneurship research more doubtful. Moreover, despite the meticulous efforts for conducting research, the PLS data analyses based on contaminated data by common method bias may mislead decision that can lead to increased costs, risks, and higher operational inefficiencies. Effects of common method bias on conclusions about hypothesis 
results should be carefully analyzed because biased responses result into inaccurate estimates of impacts and relationships between variables (Yüksel, 2017). Thus, it is imperative to report results based on data without CMV issues to suggest effective decisions and managerial implications. Therefore, the researchers are suggested to address the issue of CMV seriously while conducting research in the entrepreneurship field and employ procedural and statistical remedies to detect and control its impacts on the study's findings. In line with the recommendations of Gefen, Straub, and Rigdon (2011), we do strongly recommend using statistical remedies to identify and correct CMV impacts from PLS study's results.

Many statistical remedies are only applicable to structural equation modeling (SEM). For instance, Liang et al. (2007) proposed Common Latent Factor (CLF) approach to use with PLS analysis. Since it was the first time that an approach had been made available for PLS users in order to control CMV (Rönkkö \& Ylitalo, 2011). Liang et al. (2007) approach for PLS models involved the indicators of all the principal constructs' indicators and each indicator's variances, thus, the latent variable used to represent CBV is just an aggregate of all manifest variables used in the study without any unique observed indictors. This is also known as Unmeasured Latent Marker Construct (ULMC) (Chin, Thatcher, \& Wright, 2012). Although, the method of Liang et al. (2007) quickly became popular in IS journals. However, recent analysis on the CLF approach shows that the method does neither detect nor control for CMV (Rönkkö \& Ylitalo, 2011). In contrast, Rönkkö and Ylitalo (2011) proposed PLS marker variable modeling approach that involved 6 steps. However, this approach is also not appropriate to use for PLS models. This is because the availability of indicators of the marker variable is the most constraining factor for the application of this approach. Their results suggest that the ideal number of items of marker variable depends on the number of data as well as on the amount of method variance in the data. Thus, in the case of only a small amount of method variance, it is not necessary to control since it does not impact the path coefficient estimates. However, for the moderate amount of method variance, marker indicators should be roughly one tenth of the sample size. On the other hand, for data with severe problems of method variance, this amount needs to be doubled (Rönkkö \& Ylitalo, 2011). Thus, the PLS marker variable approach suggested by Rönkkö and Ylitalo (2011) should not be considered for PLS models. This is because once severe issue of CMV has been detected in study, then it would be difficult for PLS researchers to get a large number of marker indicators in order to control CMV. Likewise, CFA marker technique has been strongly suggested by Williams et al. (2010) that was adapted from the correlation marker technique but is used for covariance-based SEM only. Moreover, CFA marker technique uses a theoretically unrelated marker construct to model CMV with paths to each of its indicators and paths to the other latent variables in the nomological network. Thus, the shared variance between the marker and the other latent variables indicates CMV (Williams et al., 2010; Richardson et al., 2009; Lindell \& Whitney, 2001). However, CFA marker technique is relatively unproven as well as underutilized (Chin et al., 2012). Moreover, Williams et al. (2010)'s CFA marker technique requires a set of assumptions including large sample size, continuous data, multivariate normal data, independent observations, and correctly specified model. Thus, CFA marker technique is inappropriate for PLS models that generally use small sample size and non- 
normal data. Thus, the above studies highlight some statistical approaches to detect or control CMV from SEM studies. In addition, it is crucial to address the issue of CMV in study to ensure the consistency and validity of the results without common method bias. Furthermore, from a review of 110 articles on leadership in top journals, Antonakis, Bendahan, Jacquart, and Lalive (2010) found that researchers fail to address $66 \%$ to $90 \%$ of design and estimation conditions that make their causal claims invalid. They suggested researchers to plan and evaluate their work to ensure the consistency of estimates and validity of the inferences. Therefore, they proposed 10 best practices implicating analysis and research design issues. Among their proposed 10 best practices, avoiding commonmethod bias is one of the practices to obtain consistent and valid estimates in study. Thus, CMV has been recognized as a major issue by the researchers in survey design that has potential to affect the consistency and validity of PLS estimates.

The recent studies have associated the risk of common method variance with the studies involving the same survey respondents (Yüksel, 2017; Palmatier, 2016; Guide \& Ketokivi, 2015; Gefen et al., 2011; Chang et al., 2010). Richter, Cepeda, Roldán, and Ringle (2015) have acknowledged that the techniques of common method variance analysis as proposed by Chin, Thatcher, Wright, and Steel (2013) are among the major methodological contributions in the domain of PLS-SEM. In line with Richter et al. (2015), this study also acknowledges the importance of CMV techniques proposed by Chin et al. (2013) in identifying as well as controlling the impacts of CMV from any study using PLS-SEM approach.

This paper describes the most common or most recommended statistical remedies that can either be used before or after data analysis. The recommended statistical remedies from existing literature are as follow:

(1) Harman's Single-Factor Test.

(2) Partial Correlation Procedures

(i) Partialling Out of General Factor

(ii) Partialling Out a Marker Variable Lindell and Whitney (2001) method)

(iii) Partialling Out a "Marker" Variable Podsakoff et al. (2003)

(3) Correlation Matrix Procedure

(4) The Measured Latent Marker Variable Approach

(i) Construct Level Correction (CLC) Approach

(ii) Item level correction (ILC) Approach

The researchers should use the combination of above statistical remedies before analyzing the data. However, Construct Level Correction (CLC) approach and the Item level Correction (ILC) approach is recommended to use after the analysis of measurement and structural models to observe the impacts of CMV on $R^{2}$ values and on path coefficients. 


\section{An Annotated Example: A Study on Business Owners'}

\section{Entrepreneurial Competencies and Business Growth}

Here we present an empirical study to illustrate the challenge of common method bias by investigating the impact of business owners' competencies on their business growth. The concept of entrepreneurial competencies has attracted great attention in the entrepreneurship literature in recent decades. A number of studies have acknowledged the huge impact of entrepreneurial competencies of business owners in achieving the growth performance of their businesses (Sajilan, Tehseen, \& Adeyinka Ojo, 2016; Tehseen \& Ramayah, 2015; Tehseen, Sajilan, Ramayah, \& Gadar, 2015; Ahmad, 2007; Ahmad, Halim, \& Zainal, 2010). Entrepreneurial competencies refer to the knowledge, skills, and abilities that result towards business growth (Ahmad, 2007; Bird, 1995). Entrepreneurial competencies of business owners have been widely studied across various countries. However, there is a dearth of research on entrepreneurial competencies of business owners in the multicultural society like Malaysia. Thus, to fill this research gap and in line with Ahmad (2007)'s recommendations, this study has examined the entrepreneurial competencies of wholesale and retail SMEs business owners from thirteen states of West Malaysia. The data was collected from 450 business owners including Malaysian Chinese, Malay, and Malaysian Indian business owners. The researcher carried out a pre-testing of survey questionnaire among six business owners before conducting the pilot study and final data collection. This illustration is a part of a huge survey among ethnic business owners. For the purpose of illustration, we have selected only two entrepreneurial competencies namely strategic competency and ethical competency to examine their influence on business growth. Therefore, there are two independent variables (strategic competency and ethical competency) and one dependent variable (business growth) in this example. The items for these constructs were adopted from previous studies. Five point Likert scale was used to measure the items of both independent variables and dependent variable. Moreover, data was collected from only business owners to measure the variables of interest. Thus, this single source of data may produce common method bias in this study. Furthermore, all items were positively worded and were measured using the same scale, which can also lead to potential common method bias. Thus, in this study, we may expect that single respondent and items' characteristics are the main sources of common method bias. The social desirability of respondents may lead to common method bias. For instance, the respondents may want to look more competent and may want to show high growth of their businesses due to which they may choose extreme responses. This may produce high correlation among the independent and dependent variables. This will have an impact on data analysis and lead to falsify conclusions. Thus, it is important to control and test the common method bias by using combinations of available statistical remedies. This study has used SMART PLS to analyze the data, thus, most of the above statistical approaches are more suitable to control and test CMV through SMART PLS software. The applications of above statistical remedies on this study are described as below: 


\section{Harman's Single-Factor Test}

It is the most common test that is carried out by the researchers to examine the CMV in their studies. A Harman one-factor analysis is a post hoc procedure that is conducted after data collection to check whether a single factor is accountable for variance in the data (Chang et al., 2010). In this method, all items from every construct are loaded into a factor analysis to check whether one single factor emerges or whether single general factor results to the majority of the covariance among the measures; if no single factor emerges and accounts for majority of the covariance, this means that CMV is not a pervasive issue in the study (Chang et al., 2010). This test is done by using principal component analysis in SPSS. The following steps are involved while conducting this test:

(1) Enter all items of understudy constructs into factor analysis and run the principal component analysis.

(2) Look at the unrotated factor solution and examine it to assess the number of factors that could cause the variance in the variables.

(3) The presence of substantial CMV is evident if a single factor will emerge from the factor analysis or one general factor will lead to the majority of the covariance among the measures Podsakoff et al. (2003).

\section{Illustration of Harman's Single-Factor Test}

First of all, we entered all items of two exogenous latent constructs (strategic competency and ethical competency) and one endogenous latent construct (business growth) into SPSS file. Clicked on "Analyze" (Dimension Reduction Factor). Loaded all items into factor analysis, clicked Rotation (none) then continued and ok. The output generated (see table 1). The generated PCA output revealed 11 distinct factors accounting $60 \%$ of the total variance. The first unrotated factor captured only $34 \%$ of the variance in data. Thus, the two underlying assumptions did not meet, i.e. no single factor emerged and the first factor did not capture most of the variance. Therefore, these results suggested that CMV is not an issue in this study.

\section{Disadvantages of Harman's Single-Factor Test}

Although this test is easy to conduct but it has some drawbacks as well. For instance, Podsakoff et al. (2003) explained that Harman's test is insensitive; therefore, the claim regarding CMV through this test is incomplete. It is improbable that a general-factor model will fit the data, and no useful guideline is available regarding the acceptable percentage of explained variance by a single-factor (Chang et al., 2010). Moreover, we have also noted that this test only provides information regarding the absence or presence of CMV. But it cannot control or correct the common method bias that might present in the study. 
Table 1

Harman's single-Factor Test

Extraction Method: Principal Component Analysis

\begin{tabular}{ccccccc}
\hline Component & \multicolumn{3}{c}{ Initial Eigenvalues } & \multicolumn{3}{c}{ Extraction Sums of Squared Loadings } \\
\cline { 2 - 6 } & Total & \% of Variance & Cumulative \% & Total & \% of Variance & Cumulative \% \\
\hline 1 & 3.807 & 34.61 & 34.61 & 3.807 & 34.612 & 34.612 \\
2 & 1.663 & 15.11 & 49.73 & 1.663 & 15.118 & 49.730 \\
3 & 1.219 & 11.086 & 60.81 & 1.219 & 11.086 & 60.817 \\
4 & 0.784 & 7.123 & 67.94 & & & \\
5 & 0.640 & 5.818 & 73.75 & & & \\
6 & 0.607 & 5.514 & 79.27 & & & \\
7 & 0.563 & 5.115 & 84.38 & & & \\
8 & 0.489 & 4.445 & 88.83 & & & \\
9 & 0.475 & 4.321 & 93.15 & & & \\
10 & 0.419 & 3.810 & 96.96 & & & \\
11 & 0.334 & 3.037 & 100.0 & & & \\
& \multicolumn{7}{c}{}
\end{tabular}

\section{Partial Correlation Procedures}

The literature has highlighted different variations of the partial correlation procedures to control the influence of CMV. These include partialling out of general factor Podsakoff and Todor (1985); partialling out of a marker variable Lindell and Whitney (2001); and partialling out a "Marker" variable Podsakoff et al. (2003) method). All of these statistical techniques are similar as they use a measure of assumed method variance source as a covariate in statistical analysis. However, they are different with respect to specific nature and measurement of the source Podsakoff et al. (2003). For instance, the partialling out of general factor uses the score of the first unrotated factor which is obtained during the principal component analysis. On the other hand, partialling out a "Marker" variable approaches use items of social desirability that are unrelated measures to other measures of main constructs and are not the main part of study hypotheses. Before explaining the partial correlation procedures, it is important to address the concept of social desirability.

Podsakoff et al. (2003) have highlighted that social desirability refers to the need for culturally, socially right behaviors. It has been viewed as the tendency of individuals to indicate themselves in the most favorable way, regardless of their true emotions on the given topic (Podsakoff et al., 2003). The social desirability factor was introduced in the early 1930's (Ganster et al., 1983). This tendency of individuals has potential to bias their responses and to mask the true variables' relationships (Ganster et al., 1983). Therefore, the measures of the social desirability factor are used to represent the common method variance, the structural relationships among independent and dependent variables are observed with and without the measures of social desirability items to assess their influence on the estimated relationships. Although, the social desirability factor was introduced in early 1930's but Crowne and Marlowe developed the scale to measure social desirability factor in 1960. Their original scale consisted of 33 items (see Crowne and Marlowe (1960)). Later on, many scholars developed short forms of their original social desirability factor scale (Fischer \& Fick, 1993; Reynolds, 1982; Ramanaiah, Schill, \& Leung, 1977; Strahan \& Gerbasi, 1972). Therefore, the researchers have different options to use any short form of social desirability items scale to assess the impact of common method 
bias. However, this paper has adopted shortened version (X1) of items to measure the social desirability factor that was provided by Fischer and Fick (1993). We had included the 7 items of shortened version (X1) in our survey questionnaire during original data collection.

\section{Partialling Out of General Factor}

Podsakoff and Todor (1985) argued that the first unrotated factor that is driven from factor analysis extracts the great proportion of common bias across all variables. Thus, this factor describes the best estimate of method variance or respondent's generalized set of responses. Therefore, the impact of this first common factor on the relationships among understudy variables can be assessed by partialling out this factor (Podsakoff \& Todor, 1985). The common factor or general factor can be easily partiall out by utilizing SMARTPLS. Five steps are involved in the analyses of the first common factor. These steps are explained as below:

(1) The factor scores for all respondents are calculated on the first unrotated factor and are then transferred into a file of raw output data.

(2) These scores are then added as another variable "general factor" to the cases' file on existing data set and this file is transferred into the smart-PLS software.

(3) The whole research model is constructed and $R^{2}$ value of endogenous construct is observed.

(4) Then the general factor is added to the endogenous construct, after adding this factor, the $R^{2}$ value of endogenous construct is again observed and the difference between $R^{2}$ value before adding the general factor and after adding the general factor is calculated.

(5) If there is a significant increase in the $R^{2}$ value of endogenous construct after adding the general factor, then this means that there is a major issue of common method bias in the study. On the other hand, if addition of this general factor results into small increase in $R^{2}$ value of endogenous construct, then this reveals that common method bias is not a threat in the study.

Note: In the case of more than one endogenous constructs in a given model, the general factor has to be added to all endogenous constructs and their $R^{2}$ values are then observed before and after adding the general factor to assess the CMV in the study.

\section{Illustration of Partialling Out of General Factor in PLS Model}

We applied above steps to generate the general factor through principal component analysis and saved its score as another variable on SPSS file. The data was then transferred into Smart-PLS software version 3.2.4. The research model was constructed that constituted two independent latent variables (exogenous latent constructs; i.e. strategic competency 
and ethical competency) and one dependent latent variable (endogenous construct; i.e. business growth). The $R^{2}$ value of the endogenous construct before and after adding the general factor was observed. The figure 1 shows that the $R^{2}$ value of business growth was 0.044 before adding the general factor. After adding the general factor, the $R^{2}$ value of business growth was slightly increased to 0.046 (see figure 2). Thus, adding to this factor does not lead any significant change in $R^{2}$ value of the endogenous construct, this suggests no substantial common method bias in this study.

\section{Figure 1}

$R^{2}$ Value of Endogenous Construct before Adding General Factor

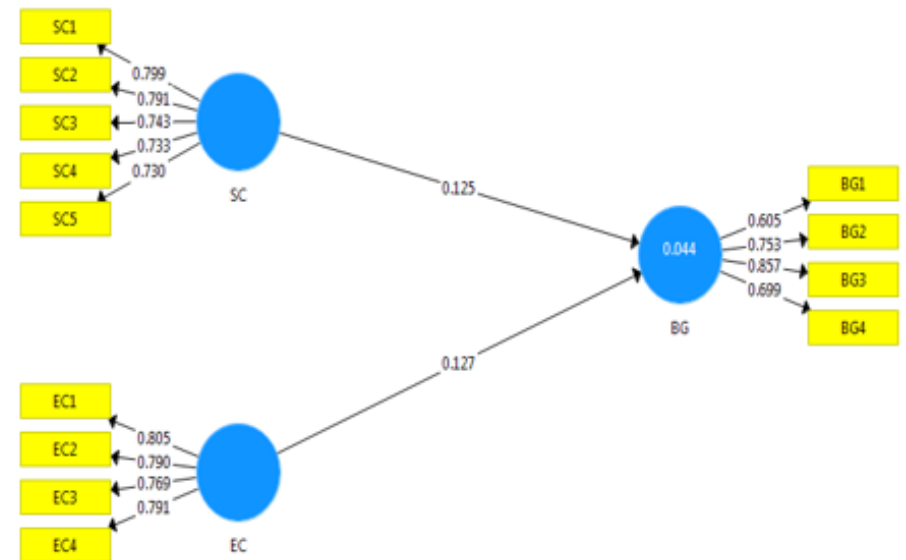

Figure 2

$R^{2}$ Value of Endogenous Construct after Adding General Factor

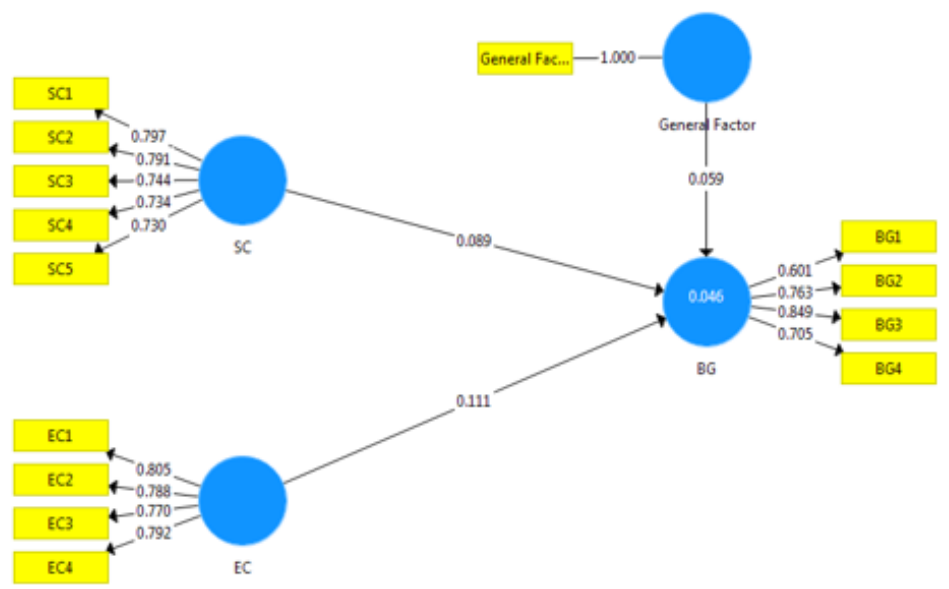




\section{Disadvantages of Partialling Out of General Factor}

Although this procedure is easy to use as researchers do not have to identify the specific source of CMV before collecting data. But it has disadvantages as well. For instance, it neglects measurement error; this method may reflect variance because of true causal relationships among the constructs and also shows CMV among the constructs' measures. Therefore, it is not possible to separate the two sources of variations by using this method. As a result, the general factor may act as another variable that produces bias estimates of parameters among the constructs of main interest (Podsakoff et al., 2003). Moreover, we have also noted that like Harman's Single-Factor Test, it only tests whether common method bias is present or absent in a study but cannot control or correct it.

\section{Partialling Out of a Marker Variable (Lindell and Whitney (2001) Method)}

This method was introduced by Lindell and Whitney (2001). A marker variable is partialled out in a PLS model to assess the common method bias by determining the correlation among the marker variable and latent variables. There would be an issue of common method bias if the correlation between any of the latent variable and marker is greater than $0.3(\mathrm{r}>0.3)$. This procedure can be carried out in PLS software by taking following steps:

(1) A model is constructed by using Smart PLS software and a marker variable (using social desirability items) is partialled out (added to the endogenous latent variable).

(2) Then the latent variable correlation is examined through PLS-Algorithm to assess the common method bias.

(3) If the correlation among any latent variables and marker variable if found to be greater than 0.3 then it means that common method bias exists in the study.

\section{Illustration of Partialling Out of Marker Variable in PLS Model}

By using the same field work data, we carried out the partial procedure according to Lindell and Whitney (2001) method examining common method bias. First of all, we used seven items of social desirability scale which were unrelated to the principal constructs of the study. These seven items were adopted from the short version (X1) of social desirability scale provided by Fischer and Fick (1993). We added these social desirability items along with our main items in the questionnaire and collected data from target respondents. After collecting the data and entering in to excel file, we imported data into Smart PLS software and drew our research model. Next, we partialled out the marker variable by adding to the endogenous latent variable (see figure 3 ). We then examined the correlation among latent variables through PLS-Algorithm (see table 2). The correlation among all latent variables and marker variable was very less than 0.3 ; this was an evidence of no common method bias in this study. 
Table 2

Correlations among Latent Variables and Marker Variable

\begin{tabular}{lcccc}
\hline & Business Growth & Ethical Competency & Marker & Strategic Competency \\
\hline Business Growth & 1 & & & \\
Ethical Competency & 0.174 & 1 & & \\
Marker & -0.139 & -0.025 & 1 & \\
Strategic Competency & 0.174 & 0.391 & -0.015 & 1 \\
\hline
\end{tabular}

Figure 3

Partialling Out of Marker Variable Lindell and Whitney (2001) Approach

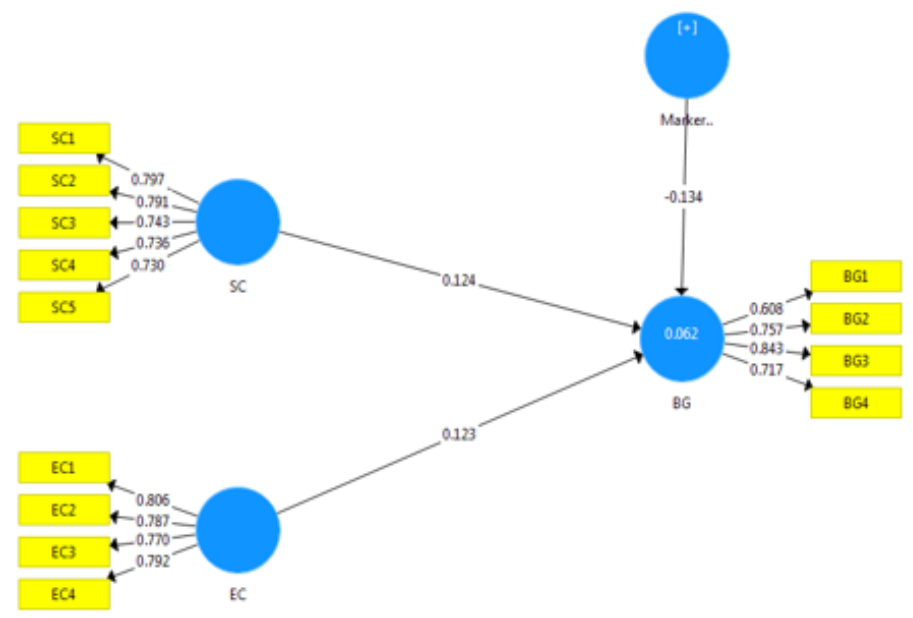

\section{Partialling Out a "Marker" Variable (Podsakoff, Mackenzie, and Pod- sakoff (2003) Method)}

The partial correlation method utilizing the theoretically unrelated marker variable was recommended by Podsakoff et al. (2003) to examine the common method bias in the study. Although Podsakoff et al. (2003) described two approaches of partial correlation methods by partialling out of social desirability items and by partialling out of unrelated marker variable. Since both approaches are similar because unrelated marker variable may compose of social desirability items as well. Partialling out a "Marker" Variable is similar to the partialling out of general factor. The only difference is the partiall out of latent marker variable instead of the general factor. This can be done by applying the following steps:

(1) Draw the hypothesized model using Smart PLS software and observe the $R^{2}$ values of all endogenous latent variables in the model.

(2) Introduce the marker variable on all endogenous constructs.

(3) Again observe the $R^{2}$ values of the endogenous constructs after adding the marker variable. 
(4) Compare the $R^{2}$ values of the endogenous constructs before and after adding the marker variable, if the significant difference is observed in the $R^{2}$ value of any endogenous construct, then is the evidence of substantial common method bias.

\section{Illustration of Partialling Out a "Marker" Variable (Podsakoff, Mackenzie, and Pod- sakoff (2003) Method)}

After applying all above steps we drew a hypothesized model using Smart PLS software and observed the $R^{2}$ value of endogenous construct (see figure 1). Then we partialled out the marker variable on endogenous

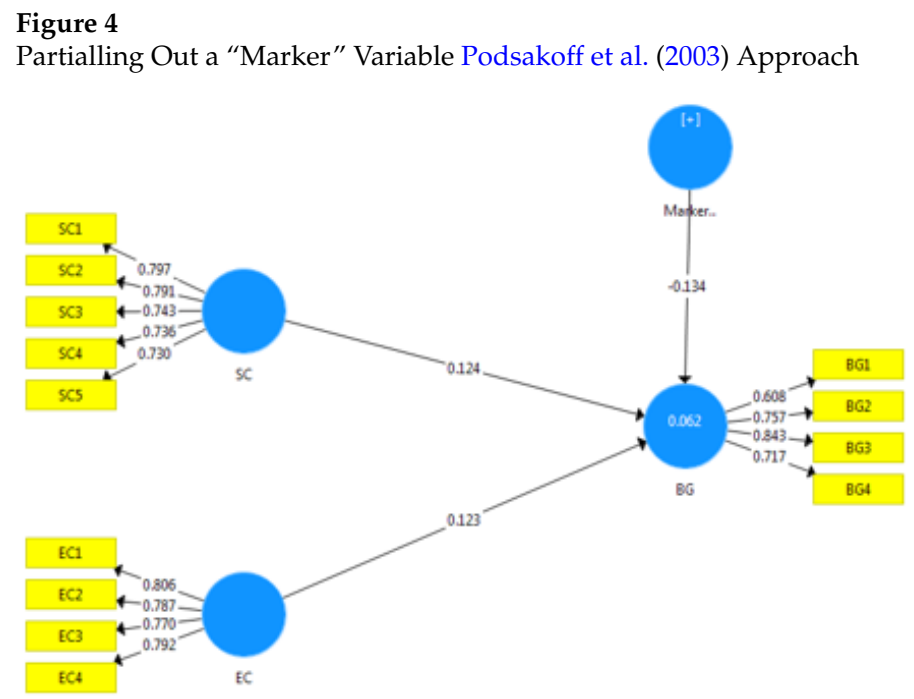

construct and again observed it's $R^{2}$ value (see figure 4). We then compared the difference between $R^{2}$ value of endogenous construct before and after adding the marker variable (e.g. $0.062-0.044=0.018$ ). Thus, the difference of 0.018 was found in the $R^{2}$ value of endogenous construct after partialling out the marker variable which is not a significant difference. This result has provided another clue of no substantial common method bias in this example.

\section{Disadvantages of Marker Variable Techniques}

Although these techniques are also easy to implement, but both techniques involve a conceptual as well as an empirical problem to control CMV. For instance, conceptually they fail to control some of main causes of CMV. Whereas, the main empirical problem with these procedures is that they ignore the measurement error (Podsakoff et al., 2003). 


\section{Correlation Matrix Procedure}

Bagozzi, Yi, and Phillips (1991) have described the method of assessing the impact of CMV through latent variables' correlations. The common method bias will be evident when a substantially large correlation is found among principal constructs $(r>0.9)$. However, CMV will be not an issue in any study if the correlation among constructs is less than 0.9 (Bagozzi et al., 1991).

\section{Illustration of Correlation Matrix Procedure}

The research model was drawn using Smart PLS software. Then the latent variables' correlation was observed through PLS Algorithm. The correlation among all the constructs was found less than 0.9 (see table 3). Thus, CMV is not an issue in this study.

Table 3

Correlations among Latent Variables

\begin{tabular}{lccc}
\hline & Business Growth & Ethical Competency & Strategic Competency \\
\hline Business Growth & 1 & & \\
Ethical Competency & 0.176 & 1 & \\
Strategic Competency & 0.175 & 0.391 & 1 \\
\hline
\end{tabular}

\section{Disadvantages of Correlation Matrix Procedure}

Like previous approaches of Harman's Single-Factor Test and Partial Correlation Procedures, this procedure only examines the presence or absence of common method bias in a study but cannot control and correct it.

\section{The Measured Latent Marker Variable Approach}

Chin et al. (2013) introduced a measured latent marker variable (MLMV) method to detect and correct CMV while utilizing partial least squares. This approach can remove the impact of CMV on structural paths. To carry out this process, multiple unrelated measures are required to be collected at the same time of data collection for primary research model. The items of Measured Latent Marker Variable (MLMV) should have no nomological relationship with other study questions while using the same scale and survey format to reflect the impacts of the common method (Chin et al., 2013). These unrelated measures are labeled as MLMV and are modeled to capture an unrevealed CMV in the data. Moreover, Chin et al. (2013) have provided some guidelines in order to select MLMV indicators to include in their data collection. These guidelines are summarized as follows:

(1) Each indicator should not belong to the same domain of constructs.

(2) Different unit of analysis should be used to draw each indicator

(3) The MLMV must constitute at least four items. 70\% of CMV can be detected and reduced by using 4 items. 
(4) MLMV should be included at the end of the well-designed survey because it is not the main purpose of the study.

Chin et al. (2013) have strongly recommended two approaches to detect and minimize the impact of CMV. The first approach is known as construct level correction (CLC). The same number of CMV control constructs as to the model's constructs are created while using CLC approach. However, each CMV control variable uses the same set of MLMV items and CMV control constructs are modeled as influencing each construct of the model.

The second recommended approach is known as item level correction (ILC). ILC involves partialling out of MLMV items in order to partial out the impacts of CMV at the level of each measurement item of the construct. In this approach, each item measure has to be regressed on all set of MLMV items. The resulted residuals for each item actually represent the construct items with the removed impact of CMV. However, the CMV should be replaced with the random error in order to assess the reliability of original items in capturing the hidden construct of interest. Therefore, $R^{2}$ is used which is obtained from each item to MLMV regression. Then the square root of the $R^{2}$ is then multiplied with specific random error of each measured item and is then added to each item residual. Then these final ILC items are used in a PLS analyses of the model.

Chin et al. (2013) claimed that second approach is more tedious but it accurately estimates the item's loading. Moreover, structural paths can be accurately estimated by using both approaches relative to other methods of detecting and minimizing CMV.

\section{Illustration of Construct Level Correction (CLC) Approach}

Figure 1 shows three constructs of PLS model and their path coefficients. Therefore, we draw three CMV control constructs involving 7 items of social desirability (unrelated measured items). The CMV control constructs were modeled to had the impact on each PLS model's construct. Then path coefficients are again estimated after introducing CMV control constructs on models' constructs (see figure 5). These obtained path coefficients of constructs are without the impact of CMV. It was observed that original estimated path coefficient of SC is 0.125 and path coefficient estimated by CLC is 0.122 , on the other hand, original estimated path coefficient of EC is 0.127 and path coefficient estimated by CLC is 0.122 . But these changes are very small and not significant, thus, we can conclude that CMV is not any issue in this study. Likewise, there were non-significant changes in other parameters as well. For instance, $t$-values of SC and EC are 2.673 and 2.646 respectively in original PLS model (see figure 7). On the other hand, t-values of SC and EC estimated by CLC approach are 2.399 and 2.498 respectively. Likewise, original R2 value in PLS model is 0.044 (see figure 1 ) and $R^{2}$ value estimated by CLC approach is 0.061 . Therefore, after removing the impacts of common method bias by CLC approach, the t-values of path coefficients are still significant. Moreover, these changes are not significant which also show that common method bias is not a serious issue in this study. However, it is important to note that any significant difference between the CLC estimation and PLS estimation would be the indication of CMV in the study. In such a case, researchers are advised to report CLC estimation instead PLS estimation to present reliable and valid estimates without any CMV affects. Additionally, if no significant difference is found between CLC 
estimation and PLS estimation, this means that there is no potential impact of CMV on the study's results, thus, researchers can safely report PLS estimates. Table 4 and Table 5 also show the CLC as well as PLS estimates of path coefficients and $R_{2}$ value respectively.

Table 4

Comparison of Path Coefficients and t-Values by CLC Approach and Original PLS Models

\begin{tabular}{lcccc}
\hline Relationships & $\begin{array}{c}\text { CLC Estimation } \\
\text { (Path coefficients) }\end{array}$ & $\begin{array}{c}\text { Original PLS Estimates } \\
\text { (Path coefficients) }\end{array}$ & $\begin{array}{c}\text { CLC Estimation } \\
\text { (t-value) }\end{array}$ & $\begin{array}{c}\text { Original PLS Estimates } \\
\text { (t-value) }\end{array}$ \\
\hline Ethical Competency ->Business Growth & 0.122 & 0.127 & $* * 2.498$ & $* * 2.646$ \\
Strategic Competency ->Business Growth & 0.122 & 0.125 & $* * 2.399$ & $* * 2.673$ \\
\hline Note: Critical t-values $* * 1.96$ (significance level=5\%), and & $* * * 2.57$ (significance level=1\%) & &
\end{tabular}

Table 5

Comparison of $R^{2}$ Values by CLC Approach and Original PLS Models

Endogenous Construct CLC Estimation $\left(R^{2}\right) \quad$ Original PLS Estimates $\left(R^{2}\right)$

Business Growth $\quad 0.061$

Figure 5

Construct Level Correction (CLC) Approach (PLS Algorithm Estimations)

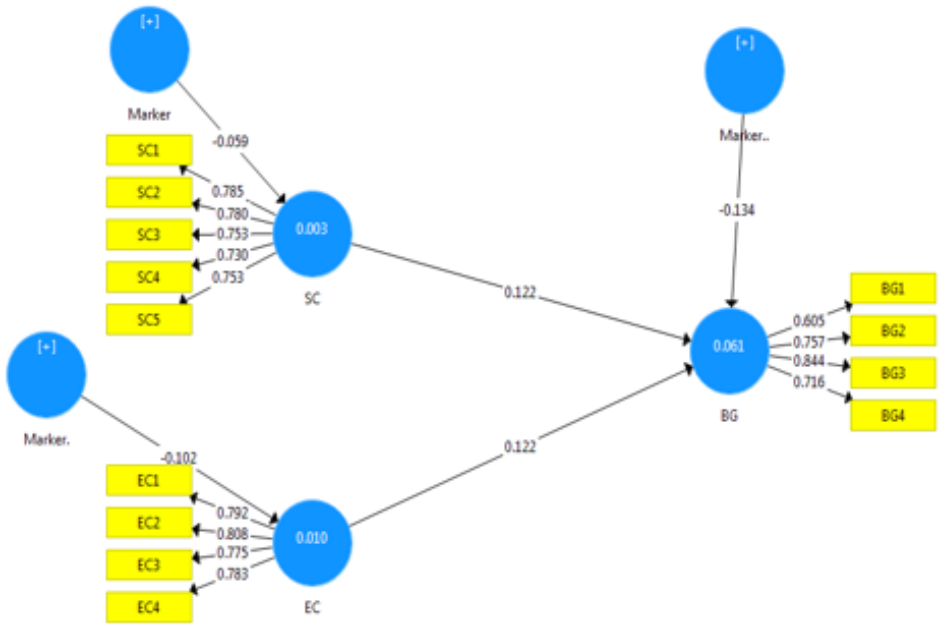

\section{Illustration of Item Level Correction (ILC) Approach}

First of all, we drew marker variable (with all 7 items of social desirability scale) as an exogenous construct and drew all items of the constructs as an endogenous construct. In this way, marker variable was drawn to have its impact on each item of the constructs (see figure 8). Then we saved inner model residuals scores (obtained from PLS Algorithm) of each item on an excel sheet. We then calculated the $R^{2}$ values and took their square roots for each of the items. Then we bootstrapped the model and obtained standard deviation (standard error) for every item. After doing so, we multiplied the standard deviation of each item with its respective square root of $R^{2}$ and added to each item's residual scores 
using excel function.

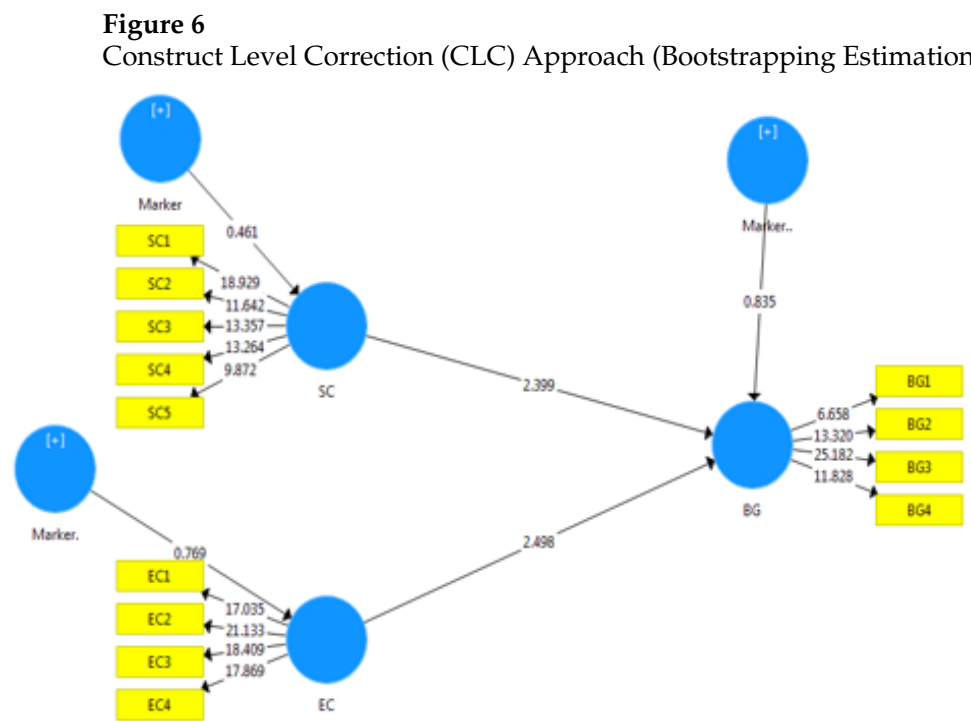

Figure 7

Original PLS Bootstrapping Estimations

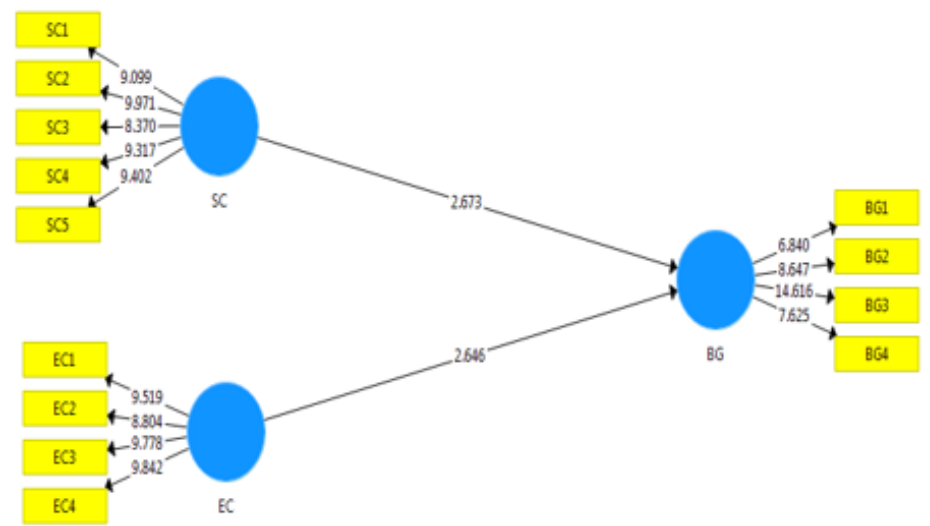

Then it was saved as another project named as ILC model. It was then imported into Smart PLS software and now PLS model was drawn by using items' residual scores. We observed no significant change in any of the parameter values while comparing the ILC model with original PLS model. Figure 9 shows the path coefficients of the exogenous constructs and $R^{2}$ value of the endogenous construct in ILC model. Figure 10 shows the $\mathrm{t}$-values of the path coefficients of constructs in ILC model. The findings revealed minor changes in path coefficients, $\mathrm{t}$-values, and the $R^{2}$ value of the constructs in ILC model. For instance, path coefficient of SC remained unchanged, while path coefficient of EC de- 
creased from 0.127 to 0.124 in ILC model. Similarly, t-values of SC decreased from 2.646 to 2.532 and EC increased from 2.673 to 2.887 in ILC model (see table 6). Whereas, $R^{2}$ value of endogenous construct decreased from 0.044 to 0.043 in ILC model (see table 7). Thus, these non-significant changes show that common method bias did not influence significantly on the relationships among variables, on variance explained by exogenous constructs, and also on the significance of the relationships among constructs. Therefore, CMV is not considered an issue for this study. However, it is important to note that any significant difference between the ILC estimation and PLS estimation would be the indication of CMV in the study. In such a case, researchers are advised to report ILC estimation instead PLS estimation to present reliable and valid estimates without any CMV affects. Moreover, if no significant difference is found between ILC estimation and PLS estimation, this means that there is no potential impact of CMV on the study's results, thus, researchers can safely report PLS estimates.

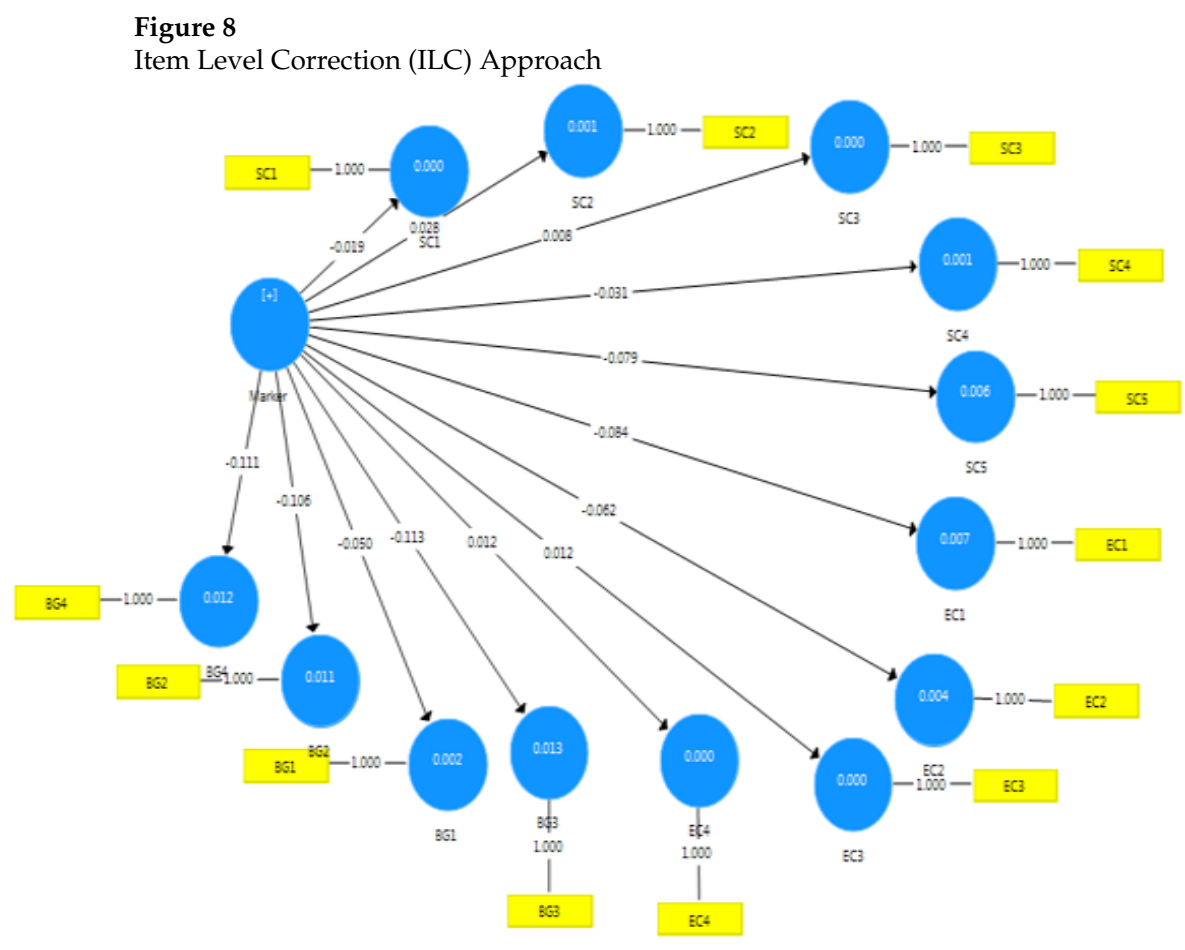

Table 6

Comparison of Path Coefficients and t-Values in ILC Model and Original PLS Model

\begin{tabular}{|c|c|c|c|c|}
\hline Relationships & $\begin{array}{l}\text { ILC Estimation } \\
\text { (Path coefficients) }\end{array}$ & $\begin{array}{l}\text { Original PLS Estimates } \\
\text { (Path coefficients) }\end{array}$ & $\begin{array}{l}\text { ILC Estimation } \\
\text { (t-value) }\end{array}$ & $\begin{array}{c}\text { Original PLS Estimates } \\
\text { (t-value) }\end{array}$ \\
\hline Ethical Competency ->Business Growth & 0.124 & 0.127 & $* 2.532$ & $* * 2.646$ \\
\hline Strategic Competency $->$ Business Growth & 0.125 & 0.125 & $* * * 2.887$ & $* * 2.673$ \\
\hline
\end{tabular}




\section{Figure 9}

ILC Model (PLS Algorithm)

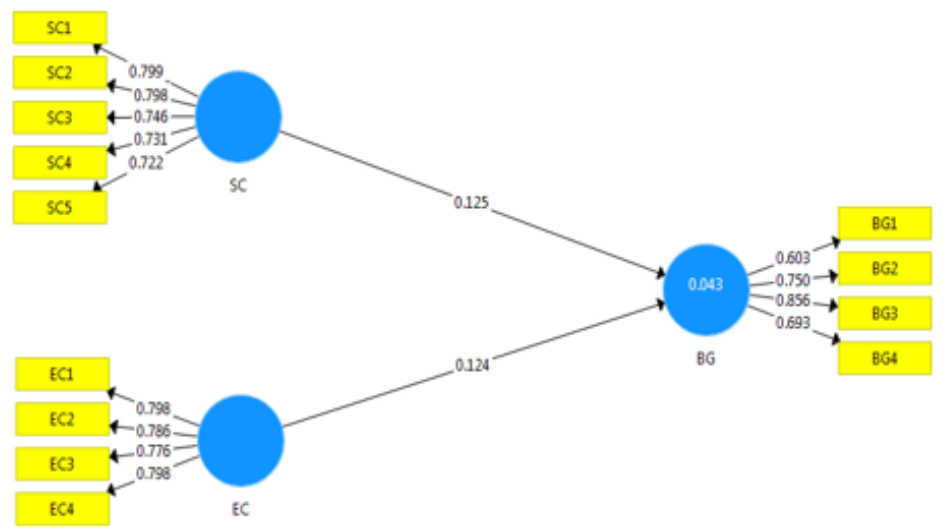

\section{Figure 10}

ILC Model (PLS Bootstrapping)

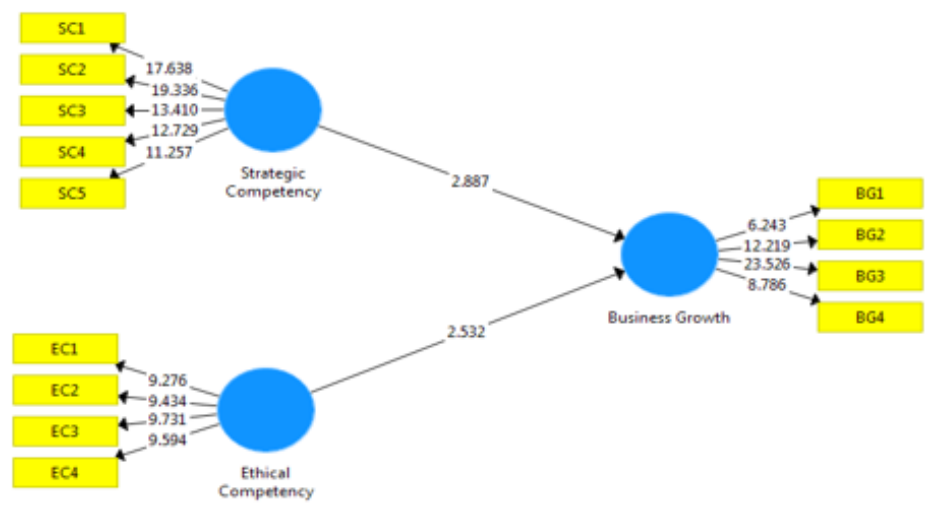

Table 7

Comparison of $R^{2}$ Values in ILC Model and Original PLS Model

\begin{tabular}{lcc} 
Endogenous Construct & ILC Estimation $\left(R^{2}\right)$ & Original PLS Estimates $\left(R^{2}\right)$ \\
\hline Business Growth & 0.043 & 0.044
\end{tabular}

\section{Discussion and Conclusion}

Surveys are considered as an important source of information in entrepreneurship research. Moreover, surveys provide measures of the independent as well as dependent variables in data analysis. In a general practice, when the researchers collect data from 
same respondents to obtain information on both independent and dependent variables, then, the concern over common method variance or same-source bias arises. Because the single source responses may create the problem of common method bias while estimating the correlation among the variables. Furthermore, CMV has been considered as a key source of bias especially while analyzing the survey studies, and is continuously aggravating attention among PLS researchers. However, the several tools that exist to control CMV in SEM are mostly developed for CB-SEM that cannot be applied for PLS models. This study has introduced various methods for controlling CMV in the context of PLS path modeling. In addition, the results suggest that the proposed statistical approaches can detect the bias caused by common method variance in PLS estimates as well as can correct the CMV bias. The common method bias is a serious issue that has attracted great attention as a topic in the organizational research. Since at the organizational level researches, it is difficult to get multiple sources to collected data, thus, it is crucial for researchers to take all essential steps/remedies to control and remove the common method bias while collecting data from a single source. Moreover, organizational level research has become important in the field of entrepreneurship, where researchers are used to collect organizational level data usually from single respondent to represent his/her firm. Therefore, it is crucial to address the issue of common method bias.

The survey designs as well as measurement of common method bias are the best ways to minimize the effect of common method bias from the study. Researchers can find a comprehensive discussion to minimize common method bias while designing surveys in MacKenzie and Podsakoff (2012). Furthermore, the researchers should investigate the challenge of common method bias more seriously in their studies by using multiple statistical approaches. Moreover, the researchers should include items of social desirability in their survey questionnaire while collecting data from same respondents on both the independent variable and dependent variable. The two MLMV approaches are more effective to remove the impact of common method bias from the study. Both these statistical approaches depend on the social desirability items that are theoretically unrelated to main items of research interest. However, the use of MLMV approaches suggested by Chin et al. (2013) are not much used in the entrepreneurship research in which mostly the same type of the respondents are the only source of obtaining the information for all the independent and dependent variables in primary studies. This paper has provided the example that how common method bias can occur in entrepreneurship research. Therefore, it is critical to take precautions to control common method bias as it leads to false results and conclusion. The aim of this article has been to review and to summarize various procedural and statistical remedies to control common method bias. The evidence from existing studies on common method bias shows that common method biases have the significant impact on the item reliabilities, item validities, and covariation among latent constructs. This proposes that researchers must have sufficient knowledge about the approaches to test and control method biases that may be present in their studies. Moreover, we have provided step by step statistical approaches to achieve common method bias control. Several procedural remedies have been discussed that could minimize the impact of common method bias. However, if researchers could not adopt all necessary procedural remedies, 
then it becomes essential to use statistical remedies to control and remove the common method bias from data analysis. Furthermore, we have also observed that it is difficult for the researchers to follow all procedural remedies to control common method bias because they are often more expensive and time consuming. Therefore, it becomes crucial to use statistical remedies to identify and then control common method bias. We have described step by step approach to conduct the most common statistical remedies to detect common method bias. The most of the statistical remedies discussed in this paper are more suitable for PLS models. In addition, we have noted that the most common statistical remedies are Single Harmon Factor Test, Partial Correlation Procedures, and Correlation Matrix Procedure that have been widely used by the researchers to address the issue of common method bias in their studies. Although these remedies have been extensively used in existing studies but they are not sufficient to control common method bias because they all can only test the presence or absence of CMV, but do not correct the common method bias from a given study. However, the two approaches suggested by Chin, Thatcher, Wright, and Steel (2013) namely Construct Level Correction (CLC) and Item Level Correction (ILC) approaches are more effective statistical remedies as they not only assess the common method bias in a given study but can also remove the common method biases from the study. Therefore, we strongly recommend the researchers to use these two approaches in their studies in order to address the issue of CMV. Particularly, if potential CMV is found in study then researchers have to report CLC estimations or ILC estimations to draw conclusion and managerial implications based on more reliable estimates without CMV impacts. However, researchers are suggested to report PLS estimates for the purpose of drawing conclusion and managerial implications only when no potential impact of CMV is found in the study. Thus, using CLC and ILC techniques, researchers can present their findings with more confidence. On the other hand, the researchers have to recollect data if the common method bias is detected by using only commonly used statically remedies (i.e. Single Harmon Factor Test, Partial Correlation Procedures, and Correlation Matrix Procedure). Thus, it is risky to depend only on these common statistical remedies. Therefore, researchers can easily control common method biases by removing CMV through Construct Level Correction (CLC) and Item Level Correction (ILC) approaches. The CLC approach is used primarily to correct estimates for structural paths while the ILC approach can correct estimates for structural paths as well as for item loading (Chin et al., 2013). These two approaches are more suitable for PLS models and are useful as compared to other statistical remedies because once the common method bias is detected from study then researchers can remove it by using these two approaches. In such case, the researchers have to report CLC and ILC estimations which will be the true parameters, whereas, original PLS estimations will be false estimations of parameters if they involve common method bias.

The best way to avoid CMV is to design the study in such a way that minimizes the risk of obtaining data with common method variance (Podsakoff et al., 2003). However, this is not always possible and, thus, all studies using PLS should include method variance analysis as a standard part for assessing single source bias (Gefen et al., 2011). Therefore, this paper provides a comprehensive review of different aspects of this key methodological issue. In addition to that, it illustrates and compares the widely recognized approaches to 
detect and/or control the systematic variance caused due to the common method used. Nevertheless, it is expected to be helpful for those researchers who desire to learn how to utilize different approaches in their study to address the issue of common method variance through PLS software. The prime focus of this paper is on addressing the critical methodological issue, "the Common Method Variance", hence, it is expected to contribute in the application of various approaches in the domain of CMV. This is because of the limited CMV diagnostics which are available for PLS users. Therefore, the main contribution of this paper is to review the statistical remedies that can be used in the domain of PLS studies to detect as well as to control CMV. Furthermore, our paper has also provided step by step guideline to future researchers to apply the selected CMV control methods. The results of statistical approaches clearly show that CMV can be easily identified and controlled by using proposed statistical approaches. Additionally, the results of this study suggest that the proposed statistical remedies can be safely used even if small amount of CMV has been identified in the study. Thus, using the recommended CMV techniques, PLS researchers can detect as well as control any small, moderate, or large impacts of CMV from any PLS study. Thus, presenting results without common-method bias after using the recommended statistical remedies of this study will be useful to obtain the actual consistent and valid PLS estimates. The extent to which these approaches can be useful does not depend on the level of CMV present in data. We do believe that our suggested remedies can be safely added even when CMV does not exist in reality, the results are not biased as shown in the examples of this study. Therefore, we strongly recommend using the proposed CMV statistical remedies even when no CMV has been identified from PLS study to gain more confidence regarding the consistency and validity of PLS results by using these techniques. Thus, the main contribution of this paper is to improve the current understanding of CMV issue in the context of entrepreneurship research and PLS modeling by reviewing the effective statistical remedies and by providing guidelines to apply them in the domain of PLS. The results of these statistical approaches suggest that they can be employed in any PLS study to identify and control even a very small amount of CMV. Thus, PLS results can be reported with confidence without any CMV problem. Thus, using and reporting the results of our proposed approaches to detect and control CMV will result into more reliable results of PLS study. Moreover, we personally believe that these statistical approaches are worthy to use while using non-probability sampling techniques such as quota and snowball methods, same type of Likert-scale, and same type of respondents because these three scenarios may lead towards the serious problems of CMV in PLS studies. In addition, we do strongly recommend future PLS studies to seriously address the issue of CMV using our proposed approaches while conducting any firm level research in multi-ethnic society like Malaysia where it is difficult to get multiple respondents and difficult to use random sampling. Furthermore, based on our personal experience, the researchers prefer to use same type of Likert-scale in questionnaire that may lead to severe issue of CMV. Thus, the future researchers are needed to address the issue of CMV in their PLS studies and more research on this issue is recommended for further studies. In conclusion, CMV statistical approaches should become a part of standard reporting structure in the context of PLS-SEM studies. The proposed approaches should be used to detect and control the impacts of CMV from any study. Moreover, MLMV tech- 
niques namely CLC and ILC are strongly recommended to use while reporting the results of PLS to present more reliable and valid estimates without any CMV affects. 


\section{References}

Ahmad, N. H. (2007). A cross cultural study of entrepreneurial competencies and entrepreneurial success in SMEs in Australia and Malaysia. (Unpublished doctoral dissertation).

Ahmad, N. H., Halim, H. A., \& Zainal, S. R. M. (2010). Is entrepreneurial competency the silver bullet for sme success in a developing nation? International Business Management, 4(2), 67-75.

Antonakis, J., Bendahan, S., Jacquart, P., \& Lalive, R. (2010). On making causal claims: A review and recommendations. The Leadership Quarterly, 21(6), 1086-1120.

Bachman, J. G., \& O'Malley, P. M. (1984). Yea-saying, nay-saying, and going to extremes: Black-white differences in response styles. Public Opinion Quarterly, 48(2), 491-509.

Bagozzi, R. P., Yi, Y., \& Phillips, L. W. (1991). Assessing construct validity in organizational research. Administrative Science Quarterly, 36(3), 421-458.

Baumgartner, H., \& Steenkamp, J. B. E. (2001). Response styles in marketing research: A cross-national investigation. Journal of Marketing Research, 38(2), 143-156.

Bird, B. (1995). Towards a theory of entrepreneurial competency. Advances in Entrepreneurship, Firm Emergence and Growth, 2(1), 51-72.

Burton-Jones, A. (2009). Minimizing method bias through programmatic research. MIS Quarterly, 33(3), 445-471.

Campbell, D. T., \& Fiske, D. W. (1959). Convergent and discriminant validation by the multitrait-multimethod matrix. Psychological Bulletin, 56(2), 81-105.

Chang, S. J., Van Witteloostuijn, A., \& Eden, L. (2010). From the editors: Common method variance in international business research. Journal of International Business Studies, 41(2), 178-184.

Chin, W. W., Thatcher, J. B., \& Wright, R. T. (2012). Assessing common method bias: Problems with the ulmc technique. MIS Quarterly, 36(3), 1003-1019.

Chin, W. W., Thatcher, J. B., Wright, R. T., \& Steel, D. (2013). Controlling for common method variance in PLS analysis: The measured latent marker variable approach. Springer, Germany.

Crowne, D. P., \& Marlowe, D. (1960). A new scale of social desirability independent of psychopathology. Journal of Consulting Psychology, 24(4), 349-354.

Doty, D. H., \& Glick, W. H. (1998). Common methods bias: Does common methods variance really bias results? Organizational Research Methods, 1(4), 374-406.

Fischer, D. G., \& Fick, C. (1993). Measuring social desirability: Short forms of the Marlowe-Crowne social desirability scale. Educational and Psychological Measurement, 53(2), 417-424.

Ganster, D. C., Hennessey, H. W., \& Luthans, F. (1983). Social desirability response effects: Three alternative models. Academy of Management Journal, 26(2), 321-331.

Gefen, D., Straub, D. W., \& Rigdon, E. E. (2011). An update and extension to SEM lines for admnistrative and social science research. Management Information Systems Quarterly, 35(2), 3-14.

Guide, V. D. R., \& Ketokivi, M. (2015). Notes from the editors: Redefining some methodological criteria for the journal. Journal of Operations Management, 37, 5-8. doi: 10.1016/s0272-6963(15)00056-x 
Jakobsen, M., \& Jensen, R. (2015). Common method bias in public management studies. International Public Management Journal, 18(1), 3-30.

Liang, H., Saraf, N., Hu, Q., \& Xue, Y. (2007). Assimilation of enterprise systems: The effect of institutional pressures and the mediating role of top management. MIS Quarterly, 31(1), 59-87.

Lindell, M. K., \& Whitney, D. J. (2001). Accounting for common method variance in cross-sectional research designs. Journal of Applied Psychology, 86(1), 114-121.

MacKenzie, S. B., \& Podsakoff, P. M. (2012). Common method bias in marketing: Causes, mechanisms, and procedural remedies. Journal of Retailing, 88(4), 542-555.

Nederhof, A. J. (1985). Methods of coping with social desirability bias: A review. European Journal of Social Psychology, 15(3), 263-280.

Palmatier, R. W. (2016). Improving publishing success at JAMS: Contribution and positioning. Springer, Germany.

Paulhus, D. L. (1991). Measurement and control of response bias. Academic Press, USA.

Perry, J. L. (1996). Measuring public service motivation: An assessment of construct reliability and validity. Journal of Public Administration Research and Theory, 6(1), 522.

Podsakoff, P. M., MacKenzie, S. B., Lee, J. Y., \& Podsakoff, N. P. (2003). Common method biases in behavioral research: A critical review of the literature and recommended remedies. Journal of Applied Psychology, 88(5), 879-903.

Podsakoff, P. M., MacKenzie, S. B., \& Podsakoff, N. P. (2012). Sources of method bias in social science research and recommendations on how to control it. Annual Review of Psychology, 63(1), 539-569.

Podsakoff, P. M., \& Todor, W. D. (1985). Relationships between leader reward and punishment behavior and group processes and productivity. Journal of Management, 11(1), 55-73.

Ramanaiah, N. V., Schill, T., \& Leung, L. S. (1977). A test of the hypothesis about the two-dimensional nature of the Marlowe-Crowne social desirability scale. Journal of Research in Personality, 11(2), 251-259.

Reio, T. G. (2010). The threat of common method variance bias to theory building. Human Resource Development Review, 9(4), 405-411.

Reynolds, W. M. (1982). Development of reliable and valid short forms of the MarloweCrowne social desirability scale. Journal of Clinical Psychology, 38(1), 119-125.

Richardson, H. A., Simmering, M. J., \& Sturman, M. C. (2009). A tale of three perspectives: Examining post hoc statistical techniques for detection and correction of common method variance. Organizational Research Methods, 12(4), 762-800.

Richter, N. F., Cepeda, G., Roldán, J. L., \& Ringle, C. M. (2015). European management research using partial least squares structural equation modeling (PLS-SEM). European Management Journal, 33(1), 1-3.

Rönkkö, M., \& Ylitalo, J. (2011). PLS marker variable approach to diagnosing and controlling for method variance. Thirty Second International Conference on Information Systems, Shanghai 2011.

Sajilan, S., Tehseen, S., \& Adeyinka Ojo, S. (2016). A conceptual framework of the impact of entrepreneurial competencies on small and medium enterprises business 
performance in the Malaysian hospitality and tourism industry. Review of Integrative Business and Economics Research, 5(2), 47-61.

Strahan, R., \& Gerbasi, K. C. (1972). Short, homogeneous versions of the Marlow-Crowne social desirability scale. Journal of Clinical Psychology, 28(2), 191-193.

Tehseen, S., \& Ramayah, T. (2015). Entrepreneurial competencies and SMEs business success: The contingent role of external integration. Mediterranean Journal of Social Sciences, 6(1), 50-61.

Tehseen, S., Sajilan, S., Ramayah, T., \& Gadar, K. (2015). An intra-cultural study of entrepreneurial competencies and SMEs business success in whole sale and retail industries of Malaysia: A conceptual model. Review of Integrative Business and Economics Research, 4(3), 33-48.

Tourangeau, R., Rips, L. J., \& Rasinski, K. (2000). The psychology of survey response. Cambridge University Press.

Watson, D., \& Clark, L. A. (1984). Negative affectivity: The disposition to experience aversive emotional states. Psychological Bulletin, 96(3), 465-490.

Williams, L. J., Hartman, N., \& Cavazotte, F. (2010). Method variance and marker variables: A review and comprehensive CFA marker technique. Organizational Research Methods, 13(3), 477-514.

Yüksel, A. (2017). A critique of "response bias" in the tourism, travel and hospitality research. Tourism Management, 59, 376-384. doi: 10.1016/j.tourman.2016.08.003 


\section{Appendix}

Fischer \& Fick's social desirability scale (Form X1)

- I like to gossip at times.

- There have been occasions when I took advantage of someone.

- I'm always willing to admit it when I make a mistake.

- I sometimes try to get even rather than forgive and forget.

- At times I have really insisted on having things my own way.

- I have never been irked when people expressed ideas very different from my own.

- I have never deliberately said something that hurt someone's feelings.

Source: Fischer and Fick (1993) Note: All short forms of social desirability scale developed by Fischer and Fick (1993) already existed in original article of (Crowne \& Marlowe, 1960)). 